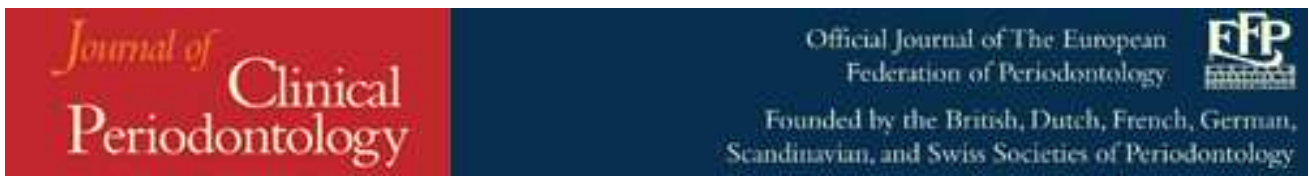

\title{
Vertical bone augmentation with 3D synthetic monetite blocks in the rabbit calvaria
}

\begin{tabular}{|r|l|}
\hline Journal: & Journal of Clinical Periodontology \\
\hline Manuscript ID: & CPE-03-11-3191.R1 \\
\hline Manuscript Type: & Original Article Pre-Clinical Sciences \\
\hline Author: & n/a \\
\hline Complete List of Authors: & $\begin{array}{l}\text { Torres, Jesús; Universidad Rey Juan Carlos, Ciencias de la Salud III } \\
\text { Tamimi, Faleh; Mc Gill University } \\
\text { Alkhraisat, Mohammad Hamdan; Universidad Complutense de } \\
\text { Madrid, Facultad de Farmacia } \\
\text { Prados, Juan Carlos; Universidad Rey Juan Carlos, Estomatology } \\
\text { Rastikerdar, Emad; Mc Gill University } \\
\text { Gbureck, Uwe; University of Würzburg, Department for Functional } \\
\text { Materials in Medicine and Dentistry } \\
\text { Barralet, Jake; Mc Gill University } \\
\text { Lopez-Cabarcos, Enrique; UCM, Fisica Quimica II }\end{array}$ \\
\hline Topic: & Implantology \\
\hline Keywords: & bone augmentation \\
\hline Main Methodology: & Animal Model \\
\hline & \\
\hline
\end{tabular}




\section{Vertical bone augmentation with $3 \mathrm{D}$ synthetic monetite blocks in the rabbit calvaria}

Torres $\mathrm{J}^{1}$, Tamimi $\mathrm{F}^{2}$, Alkhraisat $\mathrm{M}^{3}$, Prados-Frutos $\mathrm{JC}^{1}$, Rastikerdar $\mathrm{E}^{2}$, Gbureck $\mathrm{U}^{4}$, Barralet $\mathrm{J} \mathrm{E}^{2}$, López-Cabarcos $\mathrm{E}^{3}$.

\footnotetext{
${ }^{1}$ Department of Stomatology, Anatomy \& Embriology. Universidad Rey Juan Carlos, 28922, Alcorcón, Spain

${ }^{2}$ Faculty of Dentistry, McGill University, Montreal, QC, Canada H3A2B2

${ }^{3}$ Faculty of Pharmacy, Universidad Complutense, 28040 Madrid, Spain

${ }^{4}$ Department for Functional Materials in Medicine and Dentistry, University of Würzburg, D-97070, Germany
}

Corresponding author:

Jesús Torres García-Denche

Department of Stomatology, Anatomy \& Embriology; Faculty of Health Sciences, Rey Juan Carlos Univertsity, 28922 Alcorcón, Madrid, Spain.

Tel +34-913888606

e-mail: jesus.torres@urjc.es

This work was supported by Ministry of Science and Technology, (grant MAT200613646-C03-01), the postdoctoral fellow FECYT (F.T.), the UCM Program for Research Groups, MDEIE grant (F.T.), the Harry Rosen Salary award (F.T.), Canada Research Chair (J.B.), the Faculty of Dentistry at McGill University, and the Spanish Agency of International Cooperation (AECI/A011152/07). 


\begin{abstract}
Introduction

Long-term success of osteointegrated dental implants requires sufficient volume of healthy bone at the recipient sites. However, this is frequently lacking as a result of trauma, tooth loss or infection. Onlay autografting is amongst the most predictable techniques for craniofacial vertical bone augmentation, however, complications related to donor site morbidity are common and alternatives to onlay autografts are desirable.
\end{abstract}

\begin{abstract}
Aim
Develop and evaluate a new synthetic onlay block for vertical bone augmentation.
\end{abstract}

\title{
Material and methods
}

Sixteen synthetic monetite monolithic discs-shaped blocks were prepared using a 3D printing technique. The blocks were computer-designed, and had a diameter of $9.0 \mathrm{~mm}$, a thickness of either $4.0 \mathrm{~mm}(\mathrm{n}=8)$ or $3.0 \mathrm{~mm}(\mathrm{n}=8)$, and one $0.5 \mathrm{~mm}$ wide central hole that enabled their surgical fixation with osteosynthesis screws. The blocks were randomly allocated in each side of the calvaria (right or left) of 8 New Zealand rabbits and fixed with the screws in order to achieve vertical bone augmentation. Eight weeks after the surgical intervention the animals were sacrificed and the calvaria were retrieved for histological analysis. The following parameters were analyzed: the interaction between the graft and the original bone surface, the amount of bone ingrowth within the graft, and the gain in bone height achieved by the procedure. Wilcoxon t test was used for evaluated significantly differences between the two types of monetite bone blocks grafts.

\section{Results}

The blocks were easy to handle and no damage or fracture was registered while being screw-fixated to the calvarial bone. As a result, the surgical procedure was easy and quick. After a healing of 8 weeks, the synthetic blocks were strongly fused to the calvarial bone surface. Upon histological observation, the monetite blocks appeared to be infiltrated by newly formed bone, without histological signs of necrosis, osteolysis or foreign body reaction. Histomorphometry revealed that bone augmentation occurred within and over the monetite block. The 4.0 and $3.0 \mathrm{~mm}$ high blocks were filled with newly formed bone in $35 \%$ and $41 \%$ of their respective volumes. These observations indicated that craniofacial bone augmentations of at least $4 \mathrm{~mm}$ could be achieved with synthetic monetite blocks.

\section{Conclusion}

Within the limits of our study, this novel material may be able to eliminate the need for autologous bone transplantation for the augmentation of large vertical bone defects

Key words: vertical bone augmentation, implants, 3D synthetic bone graft, bone block surgery 


\section{Clinical Relevance}

\section{Scientific rationale:}

Onlay autografting is amongst the most predictable techniques for cranio facial vertical bone augmentation. However, complications related to donor site surgery are common and alternatives to onlay autografts are desirable.

Principal findings:

Craniofacial bone augmentations of at least $4 \mathrm{~mm}$ could be achieved with 3D printed synthetic monetite blocks used as onlay bone grafts.

\section{Practical implications:}

3D synthetic monetite blocks may be a suitable biomaterial for bone augmentation purposes.

\section{Introduction}

Several biomaterials and surgical techniques have been developed to facilitate implant placement in severely resorbed alveolar bone. Autografts, allografts and xenografts applied using different surgical techniques such as guided bone regeneration (GBR) and onlay block surgery have been tested (McAllister 2007).

It has been shown that vertical bone augmentation bone with different procedures and biomaterials, is possible, however, the number of complications and failures is still too high to recommend a widespread use of such procedures (Esposito 2008). Vertical GBR is a highly sensitive technique, inaccessible for many operators, that often fails due to wound dehiscence (Simion et al. 1994, Tinti et al. 1996, Tinti \& Benfenati 1998, Simion et al. 2007, Rochietta et al. 2008, Torres et al. 2010). On the other hand autograft onlay block surgery presents good prognosis at the recipient site, however, the requirement of bone harvesting is associated with higher costs and great morbidity at the donor site (Felice 2009 a,b,c). Another drawback of autograft onlays in vertical bone augmentation is their pronounced resorption, especially in sites receiving mechanical loads and soft tissue tensions (Araujo et al. 2002, Chiapasco \& Zaniboni 2011).

For these reasons, recent research has been focused on the development and evaluation of biomaterials that could replace onlay bone autografts (Felice et al. 2009, Tamimi et al. 2009, Rothamel et al. 2009, Araujo et al. 2002). However, at the present time there is no satisfactory synthetic alternative to onlay bone autografts for vertical augmentation of the alveolar bone, and therefore new biomaterials must be developed.

Recent studies have shown that the acidic calcium phosphates, brushite and monetite, are osteoconductive, osteinductive and resorb in vivo (Tamimi et al. 2006,2007,2009,2010, Alkhraisat et al. 2010 Habibovic et al. 2008). Moreover, they can be used in vertical bone augmentation procedures, and can be 3D printed allowing precise host bone-implant specific conformation. In previous studies we have shown that $2 \mathrm{~mm}$ craniofacial bone augmentation is possible with 3D printed monetite blocks. However despite this interesting finding, the amount of bone augmentation needed for implant placement is often more than $2 \mathrm{~mm}$ (Tamimi et al. 2009)

The purpose of the current study was to develop 3D printed monetite blocks and to asses its safety and efficacy in vertical bone augmentation procedures of 3.0 and $4.0 \mathrm{~mm}$ on the rabbit calvaria. 


\section{Material and methods}

\section{D Monetite bone block synthesis}

Onlay blocks were prepared using a previously described 3D printing technique (Gbureck et al. 2007). Briefly, $\alpha / \beta$-tri-calcium phosphate ( $\alpha / \beta$-TCP) was synthesized by heating a mixture of dicalcium phosphate anhydrous ( $\mathrm{CaHPO}_{4}$, monetite) (Merck, Darmstadt, Germany) and calcium carbonate $\left(\mathrm{CaCO}_{3}\right.$, calcite) (Merck, Darmstadt, Germany) in a 2:1 molar ratio to $1400{ }^{\circ} \mathrm{C}$ for $7 \mathrm{~h}$ followed by quenching to room temperature. The sintered cake was crushed with a pestle and mortar and passed through a $160 \mu \mathrm{m}$ sieve. Subsequent milling of TCP was performed in a planetary ball mill (PM400, Retsch, Germany) for 10 min. Printing of cement samples was performed with a 3D-powder printing system (Z-Corporation, USA) using the $\beta$-TCP powder and diluted phosphoric acid $\left(\mathrm{H}_{3} \mathrm{PO}_{4}\right)$ (Merck, Darmstadt, Germany) with concentration of $20 \mathrm{wt} \%$. The implant design was drafted using CAD software (Alibre design Xpress 10.0). The samples were cylindrical tablets $9.0 \mathrm{~mm}$ in diameter, either 4.0 and $3.0 \mathrm{~mm}$ thick, with a $0.5 \mathrm{~mm}$ central hole for fixation with osteosynthesis screws (Figure 1a). After printing, samples were removed from the powder bed, cleaned from residual unreacted TCP powder and stored in $20 \% \mathrm{H}_{3} \mathrm{PO}_{4}$ for $3 \times 60 \mathrm{~s}$ to increase the degree of reaction to DCPD. The blocks were then dehydrated into monetite (dicalcium phosphate anhydrous) and simultaneously sterilized by autoclaving $\left(121^{\circ} \mathrm{C}\right.$; humidity $100 \% ; 30$ min) (Gbureck et al. 2007, Habibovic et al. 2008). The final phase composition of the samples was approximately 63\% monetite and 37\% unreacted TCP (Gbureck et al. 2007), with a total porosity of $44 \%$ and a compressive strength of $15 \mathrm{MPa}$.

\section{Surgical procedure}

The surgical protocol was approved by the ethical committee for animal experiments of the Rey Juan Carlos University of Madrid. Experiments were conducted in accordance with the guidelines described by the European Communities Council Directive of 24November 1986 (86/609/EEC), and adequate measures were taken to minimize pain and discomfort to the animals.

Eight New Zealand rabbits $(3.5-4.0 \mathrm{Kg}$ ) were used for this study. The rabbits were anaesthetized, the heads were shaved and the cutaneous surface was disinfected with povidone iodine solution prior to the operation. A $\sim 5 \mathrm{~cm}$ long full depth incision was made on the linea media of the calvaria and the periosteum was separated from the bone surface with a periosteal elevator. Sixteen 3D-printed monetite blocks with heights of $3.0 \mathrm{~mm}(\mathrm{n}=8)$ and $4.0 \mathrm{~mm}(\mathrm{n}=8)$ were randomly allocated on each side of the calvarial (right or left) and secured with 5.0 and $6.0 \mathrm{~mm}$ long osteosynthesis titanium screws, respectively (AO / ASIF 4.0 self-drilling screws; Synthes, Synthes GmbH\&Co, Umkirch, Germany). In order to avoid brain damage the screws were introduced only $2.0 \mathrm{~mm}$ into de native bone (Figure 1). The incision was closed with a silk 3-0 suture. Antimicrobial prophylaxis was administered for 5 days (Oxytetracycline; Terramicina ${ }^{\circledR}$; Pfizer, Spain), and analgesia was given for pain control for 3 days (Buprenorphine Hydrochloride; Buprex ${ }^{\circledR}$; Schering-Plough, NJ). In order to better assess the bone remodelling process without increasing the number of animals tetracycline injections were given at week 4 for histological labelling of the growing bone. After an implantation period of 8 weeks the animals were sacrificed and the monolithic blocks were extracted for histological and histomorphometrical analysis on non-decalcified sections (Figure 1). 
The augmented bone area was divided into 15 smaller areas, using a $3 \times 5$ grit, in order to performed localized histomorphometrical analysis (Figure 2A). Interpolation of the localized histomorphometric values was used to depict the average distribution of bone within the blocks and provide a statistical mapping of the histological section (Renka et al. 1984) (Origin 7.0; Origin Lab Co.; Northampton; MA).

In order to evaluate the bone height gained with the onlay blocks, histological sections crossing through the screw hole at the centre of the blocks were evaluated. Direct vertical bone height measurements were not possible due to the variability in the anatomical convexity of the calvarial surface. Therefore, perceptual values of bone height gained relative to the distance between the original calvarial surface and the superior surface of the implant, were calculated every $2.0 \mathrm{~mm}$ along the mediolateral axis of the block.

\section{Statistical analysis}

The augmented bone volume, and the bone height gained were assessed for differences in the two study groups. Due to the small sample size, a non parametric Wilcoxon test for paired samples was used to evaluate differences between the two study groups: 3.0 $\mathrm{mm}$, and $4.0 \mathrm{~mm}$ high onlay blocks. Statistical significance was set at a value of $\mathrm{p}<0.05$. 


\section{Results}

\section{Clinical observations}

No complications were registered during the implantation of monetite bone blocks (Figure 1). Healing proceeded uneventfully for all 16 surgical sites during the eight weeks follow-up period, and no signs of rejection were observed. Surgical re-entry revealed that the blocks' shape and size has been preserved, and no loss of the screws or blocks was observed. Upon removal of the ostesynthesis screws, the blocks appeared to be stable and fused to the native bone indicating possible osteointegration (Figure 1D and $\mathrm{E})$.

\section{Histological observations}

Upon histological observation, the monetite blocks appeared to be infiltrated by newly formed bone, without histological signs of necrosis, osteolysis or foreign body reaction (Figure 2-4). In all histological sections, it was possible to observe intimate contact between the remaining material and the native calvarial bone at the border between the two surfaces, indicating osteointegration of the monetite blocks. Newly formed bone was observed to be covering the lateral border of the blocks, reaching the lateralsuperior surface of all the $3.0 \mathrm{~mm}$ and $4.0 \mathrm{~mm}$ high blocks (Figure $3 \mathrm{~A}-\mathrm{D}$ ). New bone formation was also observed in the inferior surface of the block at the interface with native bone, where biomaterial resorption was also apparent (Figure $3 \mathrm{~A}$ ). The screw hole in the blocks was also highly infiltrated with newly formed bone that grew along side the osteosynthesis screw from the calvarial surface up to halfway the length of the block. At higher magnification (Figure 3 B-D), the monetite blocks appeared to be highly porous and infiltrated with newly formed bone. Direct contact between newly formed bone and the remaining monetite block was observed indicating good osteoconduction properties of this synthetic material in a vertical bone augmentation application (Figure 3 D).

Histological observations suggest that the high porosity and material resorption allowed significant bone infiltration within the bone graft matrix. Monetite resorption appeared to be more pronounced on the graft-bone interface, and on the lateral margin of the implant, probably due to better perfusion in those areas (Figure 3-4).

The presence of bone within the bone block grafts was further confirmed by picro-sirius red stain which revealed the presence of collagen on the inferior and lateral-superior regions of the implants (Figure 4 A-B) (Junqueira 1979,1986,). Fluorescence microscopy revealed tetracycline deposition lines within the monetite blocks, and up to their superior end, indicating early bone formation (4 weeks after implatation) throughout the implants (Figure 4 C-D). 
Table 1. Morphometric data for each implanted block and rabbit

\begin{tabular}{|c|c|c|c|c|c|c|}
\hline \multirow[t]{2}{*}{ Rabbit } & \multicolumn{3}{|c|}{$3 \mathrm{~mm}$ blocks } & \multicolumn{3}{|c|}{$4 \mathrm{~mm}$ blocks } \\
\hline & Bone Area $\%$ & RG\% & GR\% & BA\% & RG & GR\% \\
\hline 1 & $41 \mathrm{SD} 3$ & 49 SD4 & 39 SD 5 & 36 SD 5 & 56 SD 7 & 32 SD 7 \\
\hline 2 & $25 \mathrm{SD} 1$ & 69 SD1 & $15 \mathrm{SD} 2$ & 14 SD 7 & 83 SD 9 & $0 \quad \mathrm{SD} 9$ \\
\hline 3 & $34 \mathrm{SD} 9$ & $58 \mathrm{SD} 11$ & $28 \mathrm{SD} 13$ & $22 \mathrm{SD} 8$ & 73 SD 10 & $11 \mathrm{SD} 10$ \\
\hline 4 & $49 \mathrm{SD} 4$ & 40 SD5 & $51 \mathrm{SD} 7$ & $55 \mathrm{SD} 7$ & 33 SD 9 & 60 SD 9 \\
\hline 5 & 48 SD 7 & 41 SD8 & 49 SD10 & $57 \mathrm{SD} 6$ & 30 SD 7 & 63 SD 7 \\
\hline 6 & $44 \mathrm{SD} 6$ & 46 SD8 & 43 SD9 & $50 \mathrm{SD} 2$ & $39 \mathrm{SD} 3$ & $53 \mathrm{SD} 3$ \\
\hline 7 & $33 \mathrm{SD} 2$ & $59 \mathrm{SD} 2$ & $27 \mathrm{SD} 3$ & $45 \mathrm{SD} 4$ & $45 \mathrm{SD} 5$ & 45 SD 5 \\
\hline 8 & 48 SD 7 & 41 SD8 & 49 SD10 & $17 \mathrm{SD} 4$ & 79 SD 5 & 3 SD 6 \\
\hline Mean & $40 \mathrm{SD} 8$ & 50 SD 10 & $38 \mathrm{SD} 13$ & 37 SD 17 & $55 \mathrm{SD} 21$ & 33 SD26 \\
\hline
\end{tabular}

Interpolation map of the histomorphometric analyses confirmed that bone growth within the blocks was heterogeneous, but it followed a consistent pattern (Figure 2B-D). Bone was abundant on the lateral, medial and inferior regions of the blocks, but it was very was scarce in the central-superior surface (Figure 2B,C,D).

\section{Bone height analysis}

In all of the $3 \mathrm{~mm}$ and $4 \mathrm{~mm}$ implanted blocks, new bone formation reached the top of the implant at least on the lateral side of the blocks. Accordingly the maximum bone height gained with the $4.0 \mathrm{~mm}$ blocks was significantly higher than that obtained with the $3.0 \mathrm{~mm}$ blocks $(\mathrm{p}<0.01)$. This result indicated that a $4 \mathrm{~mm}$ bone height augmentation could be obtained with the onlay 3D printed monetite blocks. Bone height levels across the blocks followed a similar pattern in both the $3.0 \mathrm{~mm}$ and the $4.0 \mathrm{~mm}$ high blocks, with no significant differences in the two groups $(\mathrm{p}>0.05)$ (Figure $2 \mathrm{~B}$ and $5 \mathrm{~A}$ ). It was observed that maximum bone levels were reached on the lateral end of the blocks, while the lowest ones were always registered at the central region of the blocks . Relatively high levels of bone height gained were also observed on the medial end of the block. The central part of the block showed the lowest levels of bone infiltration (Figure 5A). 


\section{Discussion}

In this study the monetite blocks were easy to handle, and no damage or fracture of the blocks was registered during the surgical intervention. This indicates that the mechanical quality of the 3D printed monetite blocks met the requirements needed for craniofacial surgeries. Moreover, by designing the blocks with a screw hole in the centre, screw fixation was easy and tension-free. As a result, the surgical procedure was straight forward and quick. Xenogenic derived bone blocks have already been reported to achieve vertical bone augmentation in the mandible. However, these materials are quite brittle and fragile. Consequently, these graft materials often break during and following the screw fixation process, resulting in a complicated surgical technique, and a hindered the bone graft healing process (Simion et al. 2006, Felice et al. 2009).

Within 8 weeks of implantation, the monetite blocks were macroscopically fully incorporated to the calvarial bone achieving a bone height augmentation of up to $4 \mathrm{~mm}$. To the best of our knowledge this is the first study reporting $4.0 \mathrm{~mm}$ vertical bone augmentation with synthetic onlay blocks.

Upon histological observation, the monetite blocks appeared to be infiltrated by newly formed bone, without histological signs of necrosis, osteolysis or foreign body reaction. These results were similar to those reported in previous studies where monetite based biomaterials have already proven their excellent bone compatibility upon implantation in bone defects or on bone surfaces (Tamimi et al. 2009; Tamimi et al. 2010).

Bone formation within the blocks was heterogeneous, but it followed the same pattern in all histological sections: it was always more pronounced on the lateral end of the implants. This phenomenon can be explained by the anatomical arrangement of the calvarial blood vessels in mammals. The parietal bone is supplied by the posterior branch of the middle meningeal artery that emanates from the maxillary artery. On each parietal bone, one perfused major branch of the meningeal artery runs laterally, curving towards the sagittal suture (Slotte 2005). So it is easily comprehensible that the major evidence of newly formed bone was observed in the areas of major blood supply, in other words in, the lateral side and the surface of the block in direct contact with the native bone. These results point out the importance of graft's vascularisation, as areas with better blood supply achieved more new bone formation. Moreover, a higher percentage of new bone was observed in the $3.0 \mathrm{~mm}$ high block than in the $4.0 \mathrm{~mm}$ ones. This fact was probably due to the proximity of the bone graft to the vascular supply of the native bone. Indeed in a previous study using $2 \mathrm{~mm}$ high monetite block, we observed an even higher percentage of new bone formation (43\%) compared to the $3 \mathrm{~mm}$ bone high blocks for the same implantation time (Tamimi et al 2010).

Despite its heterogeneous distribution, the total percentage of new bone within the augmented site was $40 \%$ and $37 \%$ of the 3.0 and $4.0 \mathrm{~mm}$ blocks respectively. This percentage of bone is comparable to that obtained with other bone augmentation procedures by which dental implants have been successfully stabilized (Berglundh et al. 1997, Carmagnola et al. 2003, Artzi \& Dayan 2000, Tamimi 2010). Accordingly 3D printed monetite onlay blocks might be of interest in bone augmentation procedures for dental implant placement, although future studies will have to be performed in order to 
The ostesynthesis screws used in this study only required the bone thickness of the rabbit calvaria $(\sim 2.0 \mathrm{~mm})$, in order to fixate the monetite onlay blocks. The sum of the calvaria bone thickness $(\sim 2.0 \mathrm{~mm})$ with the maximum bone augmentation obtained with the blocks $(4.0 \mathrm{~mm})$ sum $\sim 6.0 \mathrm{~mm}$. This amount of bone height is sufficient for the placement of short implants (5.0-6.0mm) (Felice 2009, Stellingsma 2004). Therefore vertical bone augmentation achieved by monetite blocks in this animal model could be a strong indicative of the potential this new technology may have for the treatment of highly resorbed mandibles ( $2.0 \mathrm{~mm}$ bone thickness left over the mandibular canal). Although further studies will have to be made in order to confirm this point.

\section{Conclusion}

Synthetic onlay blocks made of monetite, can be fixed to bone surfaces by using ostesynthesis screws, and achieve vertical bone augmentations as high as $4.0 \mathrm{~mm}$. Within the limits of this study, this novel material may eliminate the need for autologous bone transplantation for the augmentation of large vertical bone defects

\section{References}

Alkhraisat MH, Rueda CR, Blanco LJ, Tamimi FM, Torres J, Gbureck U, Lopez-cabarcos E (2010).. Effect of silica gel on the cohesion, properties and biological performance of brushite cement. Acta Biomaterialia.6:257-65

Araújo MG, Sonohara M, Hayacibara R, Cardaropoli G \& Lindhe J. (2002). Lateral ridge augmentation by the use of grafts comprised of autologous bone or a biomaterial. An experiment in the dog. Journal of Clinical Periodontology 29:1122-31 
Artzi Z, Tal H \& Dayan D (2000). Porous bovine bone mineral in healing of human extraction sockets. Part I. Histomorphometric evaluations at 9 months. Journal of Periodontology 71:1015-1023.

Bays RA. (1983). The influence of systemic bone disease on bone resorption following mandibular augmentation. Oral Surgery Oral Medicine Oral Pathology 55:223-31

Berglundh T \& Lindhe J (1997). Healing around implants placed in bone defects treated with Bio-Oss. Clinical Oral Implants Research 8:117-124

Carmagnola D, Adriaens P \& Berglundh T (2003). Healing of human extraction sockets filled with Bio-Oss ${ }^{\circledR}$. Clinical Oral Implants Research 14:137-143

Chiapasco M, Zaniboni M \& Rimondini L. (2007). Autogenous onlay bone grafts vs. alveolar distraction osteogenesis for the correction of vertically deficient edentulous ridges: a 2-4-year prospective study on humans. Clinical Oral Implants Research 18: $432-40$

Esposito M, Grusovin MG, Felice P, Karatzopoulos G, Worthington HV, Coulthard P (2010). The efficacy of horizontal and vertical bone augmentation procedures for dental implants - a Cochrane systematic review. European Journal of Oral Implantology 2: $167-84$

Junqueira LC, Bignolas G, Brentani RR (1979). Picrosirius staining plus polarization microscopy, a specific method for collagen detection in tissue sections. The Histochemical Journal 11: 447-455

Junqueira, LC, Assis Figuereido MT, Torioni H, Montes GS (1986)..Differential Histologic diagnosis of osteoid. A study on human osteosarcoma collagen by the histochemical picrosirius-polarization method. The Journal of Pathology 148: 189-196

Felice P, Cannizzaro G, Checchi V, Marchetti C, Pellegrino G, Censi P \& Esposito M (2009).Vertical bone augmentation versus 7-mm-long implants in posterior atrophic mandibles. Results of a randomised controlled clinical trial of up to 4 months after loading. European Journal of Oral Implantology 2: 7-20

Felice P, Marchetti C, Iezzi G, Piattelli A, Worthington H, Pellegrino G \& Esposito M (2009).Vertical ridge augmentation of the atrophic posterior mandible with interpositional block grafts: bone from the iliac crest vs. bovine anorganic bone. Clinical and histological results up to one year after loading from a randomizedcontrolled clinical trial. Clinical Oral Implants Research 20;1386-93

Felice P, Checci V, Pistilli R, Scarano A, Pellegrino G \& Esposito M.(2009). Bone augmentation versus 5-mm dental implants in posterior atrophic jaws. Four-month postloading results from a randomised controlled clinical trial. European Journal of Oral Implantology 2: 267-81 
Fontana F, Rocchietta I, Dellavia C, Nevins M \& Simion M (2008). Biocompatibility and manageability of a new fixable bone graft for the treatment of localized bone defects: preliminary study in a dog model. International Journal Periodontics and Restorative Dentistry 28: :601-7.

Gbureck U, Hölzel T, Klammert U, Würzler K, Müller FA. \& Barralet JE. (2007) Resorbable Dicalcium Phosphate Bone Substitutes Prepared by 3D Powder Printing. Advanced Functional Materials 17: 3940-5

Habibovic P, Gbureck U, Doillon CJ, Bassett DC, van Blitterswijk CA \& Barralet JE.(2008). Osteoconduction and osteoinduction of low-temperature 3D printed bioceramic implants. Biomaterials 29(7):944-53.

Lundgren AK, Lundgren D, Sennerby L, Taylor A, Gottlow J \& Nyman S (1997). Bone augmentation at titanium implants using autologous bone grafts and a bioresorbable barrier. An experimental study in the rabbit tibia. Clinical Oral Implants Research 8: $82-9$

Lundgren D, Lundgren AK, Sennerby L \& Nyman S (1995). Augmentation of intramembraneous bone beyond the skeletal envelope using an occlusive titanium barrier. An experimental study in the rabbit. Clinical Oral Implants Research 6: 67-72

de Macedo NL, do Socorro Ferreira Monteiro A \& de Macedo LG. (2009). Vertical bone augmentation using a polytetrafluoroethylene nonporous barrier for osseointegrated implants partially inserted in tibiae of rabbits. Implant Dentistry 18: $182-91$

McAllister BS \& Haghighat K (2007). Bone augmentation techniques. Journal of Periodontology 78: 377-96

Renka RJ \& Cline AK (1984). A triangle-based C $C^{1}$ interpolation method. Rocky mountain. Journal of Mathematics 14:223-37

Renouard F \& Nisand D (2006). Impact of implant length and diameter on survival rates. Clinical Oral Implants Research 17:35-51

Rocchietta I, Fontana F, Simion M. (2008) Clinical outcomes of vertical bone augmentation to enable dental implant placement: a systematic review. J Clin Periodontol. 35, 203-15

Rothamel D, Schwarz F, Herten M, Ferrari D, Mischkowski RA, Sager M \& Becker J (2009). Vertical ridge augmentation using xenogenous bone blocks: a histomorphometric study in dogs.; International Journal Oral Maxillofacial Implants 24: $243-50$

Schmitz JP \& Hollinger JO. (1986). The critical size defect as an experimental model forcraniomandibulofacial nonunions. Clinical Orthopaedics and Related Research 205:299-308 
Simion M, Nevins M, Rocchietta I, Fontana F, Maschera E, Schupbach P \& Kim DM (2009). Vertical ridge augmentation using an equine block infused with recombinant human platelet-derived growth factor-BB: a histologic study in a canine model. International Journal Periodontics and Restorative Dentistry 29: 245-55.

Simion M, Rocchietta I, Kim D, Nevins M \& Fiorellini (2006). Vertical ridge augmentation by means of deproteinized bovine bone block and recombinant human platelet-derived growth factor-BB: a histologic study in a dog model. International Journal Periodontics and Restorative Dentistry 26: :415-23

Simion M, Trisi P, Piattelli A. (1994) Vertical ridge augmentation using a membrane technique associated with osseointegrated implants. Int J Periodontics Restorative Dent 14, 496-511.

Simion M, Fontana F, Rasperini G, Maiorana C (2007) Vertical ridge augmentation by expanded-polytetrafluoroethylene membrane and a combination of intraoral autogenous bone graft and deproteinized anorganic bovine bone (Bio Oss). Clin Oral Implants Res 18,620-9.

Slotte C, Lundgren D \& Sennerby L (2005). Bone morphology and vascularization of untreated and guided bone augmentation-treated rabbit calvaria: evaluation of an augmentation model. Clinical Oral Implants Research 16: 228-35

Stellingsma C, Vissink A, Meijer HJ, Kuiper C \& Raghoebar GM. (2004). Implantology and the severely resorbed edentulous mandible. Critical Reviews in Oral Biolology and Medicine 8:240-8

Tamimi F, Torres J, Tresguerres I, Clemente C, López-Cabarcos E. \& Jerez Blanco L. (2006) Bone augmentation in rabbit calvaria: comparative study between Bio-oss $®$ and a novel $\beta$-TCP/DCPD granulate. Journal of Clinical Periodontology 33:922-928.

Tamimi F, Torres J, Kathan C, Baca R, Clemente C, Blanco L. \& López-Cabarcos E. (2008) Bone regeneration in rabbit calvaria with novel monetite granules. Journal of Biomedical Material Research. Part A 87:980-5.

Tamimi F, Torres J, Gbureck U, Lopez-Cabarcos E, Bassett DC, Alkhraisat MH. \& Barralet JE. (2009) Craniofacial vertical bone augmentation: a comparison between 3D printed monolithic monetite blocks and autologous onlay grafts in the rabbit. Biomaterials 30:6318-26.

Tamimi F, Torres J, Bassett D, Barralet J \& Cabarcos EL. (2010) Resorption of monetite granules in alveolar bone defects in human patients. Biomaterials 31:2762-9.

Tinti C, Parma-Benfenati S, Polizzi G. (1996) Vertical ridge augmentation: what is the limit? International Journal of Periodontics and Restorative Dentistry.16,220-9. 
Tinti C, Parma-Benfenati S. (1998) Vertical ridge augmentation: surgical protocol and retrospective evaluation of 48 consecutively inserted implants. International Journal of Periodontics and Restorative Dentistry 18,434-43.

Tonetti MS \& Hämmerle CH; European Workshop on Periodontology Group C (2008). Advances in bone augmentation to enable dental implant placement: Consensus Report of the Sixth European Workshop on Periodontology. Journal of Clinical Periodontology 35:168-72

Torres J, Tamimi F, Alkhraisat MH, Manchón A, Linares R, Prados-Frutos JC, Hernández G \& López Cabarcos E (2010). Platelet-rich plasma may prevent titaniummesh exposure in alveolar ridge augmentation with anorganic bovine bone. Journal of Clinical Periodontology 37: 943-51

Van Steenberghe D, Johansson C, Quirynen M, Molly L, Albrektsson T \& Naert I. (2003). Bone augmentation by means of a stiff occlusive titanium barrier. Clinical Oral Implants Research 14: 63-71 


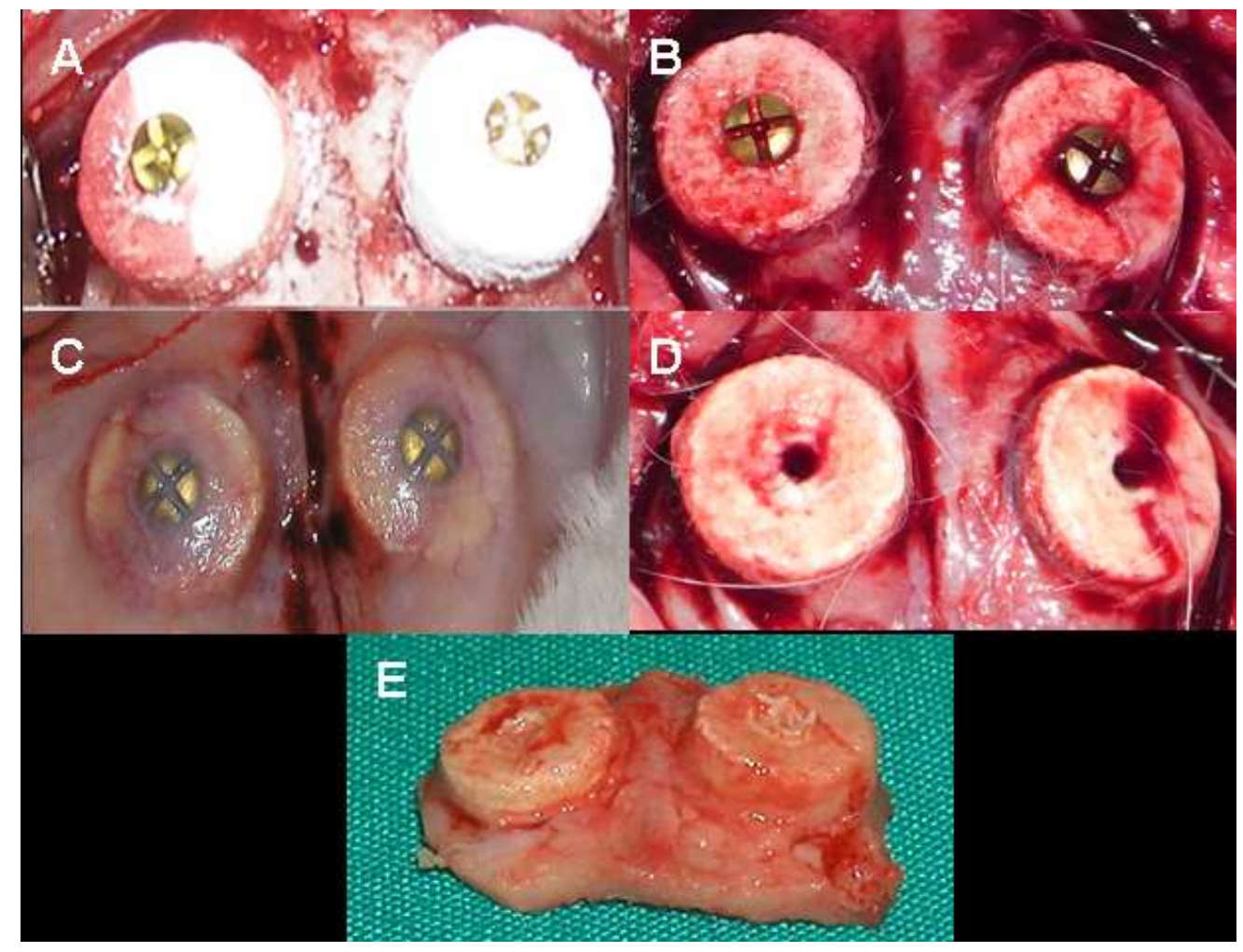

Figure 1. A: Surgical placement of the 3D printed monetite blocks. B: Photograph showing blood infiltration of the monetite block soon after surgical placement. C: Monetite blocks upon explanation (8 weeks postoperatively). D: Removal of the osteosynthesis screws upon surgical explanations. The blocks were integrated to the bone and did not move despite the removal of the screw. $\mathrm{E}$ : Calvarial bone explants including the blocks with the 2 heights studied $(3.0 \mathrm{~mm}$ and $4.0 \mathrm{~mm}$ ). $104 \times 80 \mathrm{~mm}(150 \times 150 \mathrm{DPI})$ 
A

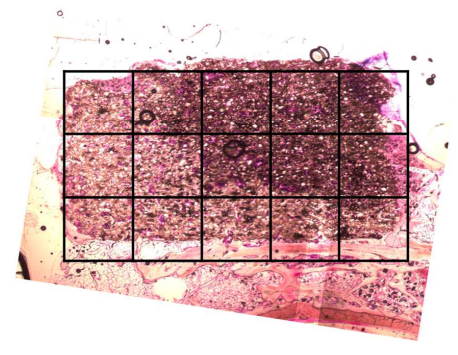

B

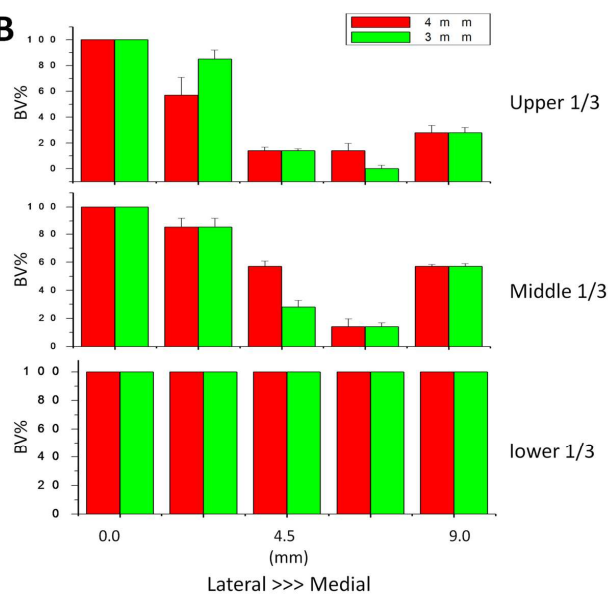

Lateral $\gg \gg$ Medial

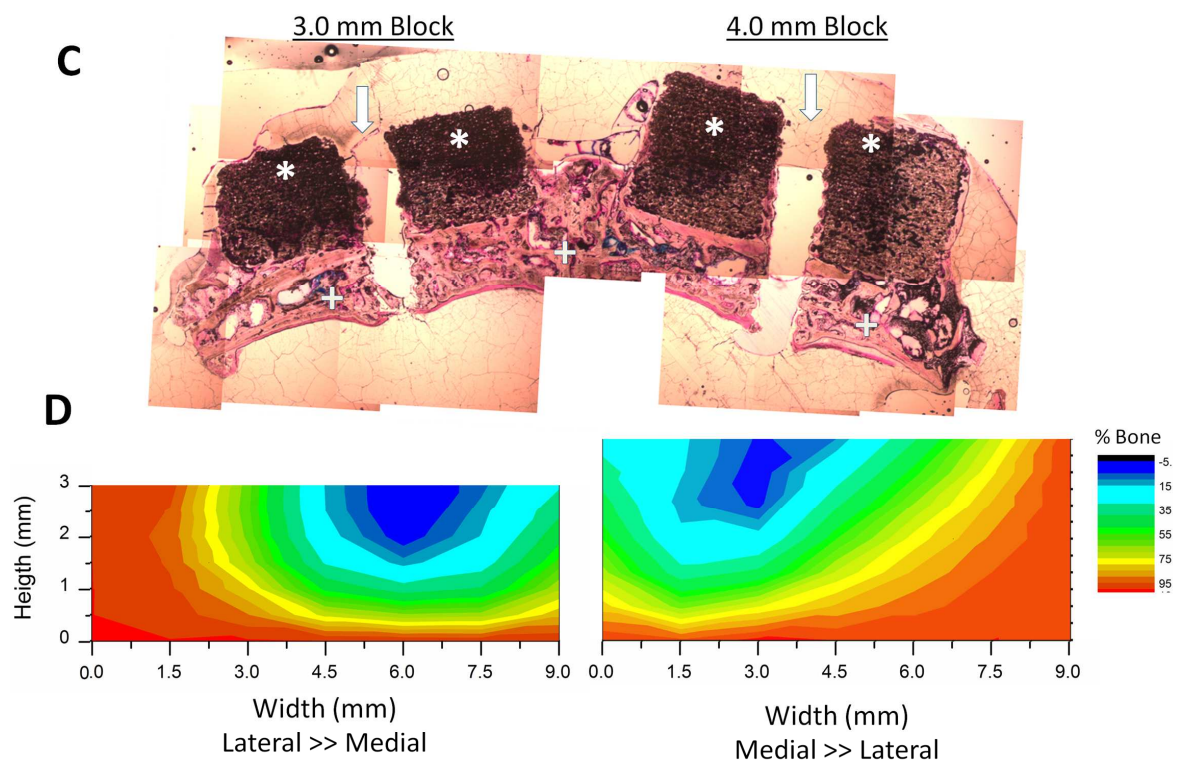

Figure 2. A: Bone block histological section divided into 15 smaller areas, using a $3 \times 5$ grit (a.u.) for histomorphometric measurements. B: Histomorphometric measurements of the areas delimited by the grit shown figure 2A. C: Coronal cross section of the $3.0 \mathrm{~mm}$ and $4.0 \mathrm{~mm}$ blocks cut through their corresponding screw hole(white arrow) showing the remaining material $(*)$, and the original calvaria surface $(+)$. D: Interpolation map created from the data presented in figure $2 \mathrm{~B}$. These maps show the averaged distribution of bone growth within the blocks. Bone formation followed a similar pattern in all the samples of the two types of blocks studied. Red colour showed intense new bone formation on the lateral side and on the entire inferior surface of the blocks. Yellow and greens colours indicated moderate bone formation in the mid-central and medial part of the block and blue depicted absence of bone formation in mid-superior, and medial-superior area of the blocks.

\section{$760 \times 1013 \mathrm{~mm}(77 \times 77 \mathrm{DPI})$}


Figure 3. Histological micrographs of the $4.0 \mathrm{~mm}$ high blocks at different magnifications (A-D). The sections were stained with methylene blue and basic fuchsine. At low magnifications, bone ingrowth can be observed on the lateral side of the blocks, in the surface in direct contact with native bone and in the screw hole (black arrows) (A). At higher magnifications, bone tissue (fucsia) can be identified infiltrating the blocks itself (dark brown) ( $B$ and $C$ ). At even higher magnifications osteocytes can be observed infiltrated within the new bone formation (white arrows) (D). $1013 \times 760 \mathrm{~mm}$ (77 x 77 DPI) 


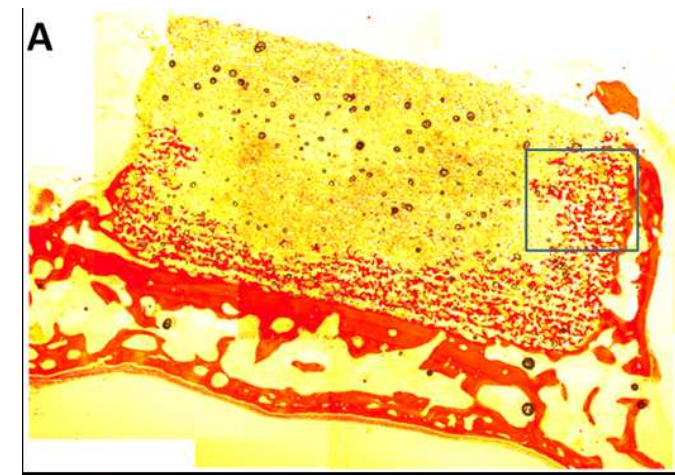

\section{B}
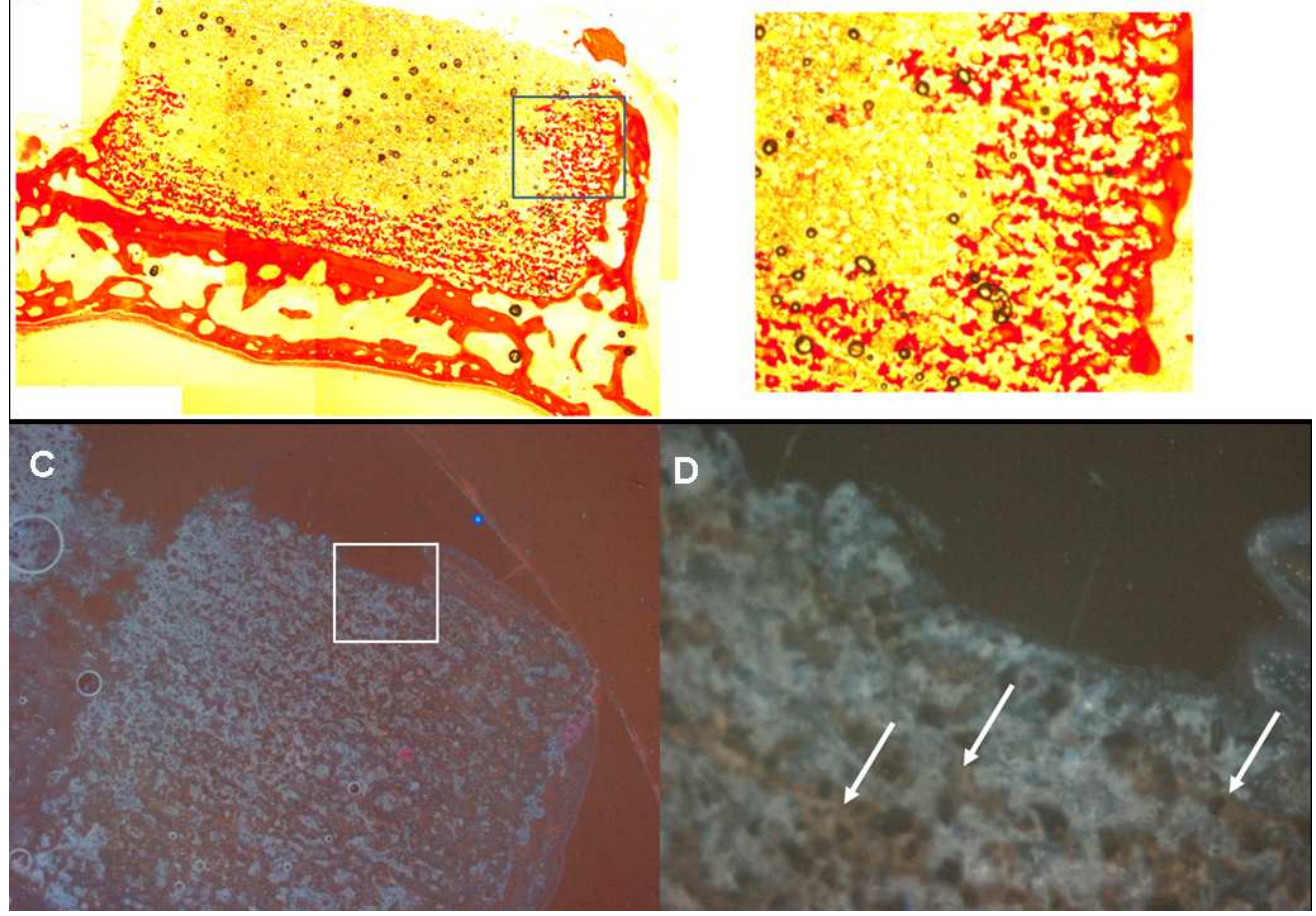

Figure 4. Histological section of 3D printed monolithic monetite implant ( $4.0 \mathrm{~mm}$ high), screwed on the calvarial bone of a rabbit. ( $A$ and $B$ )Histological micrographs of sections dyed with picros/sirius stain; the red color indicated bone/osteoid tissue; it can be observed that bone formation occurs at the top of the implant on the lateral side. C and D: fluorescence microscopy of histological sections showing tetracycline lines (white arrows) throughout the monetite block and on its superior surface.

$174 \times 128 \mathrm{~mm}(150 \times 150 \mathrm{DPI})$ 
A

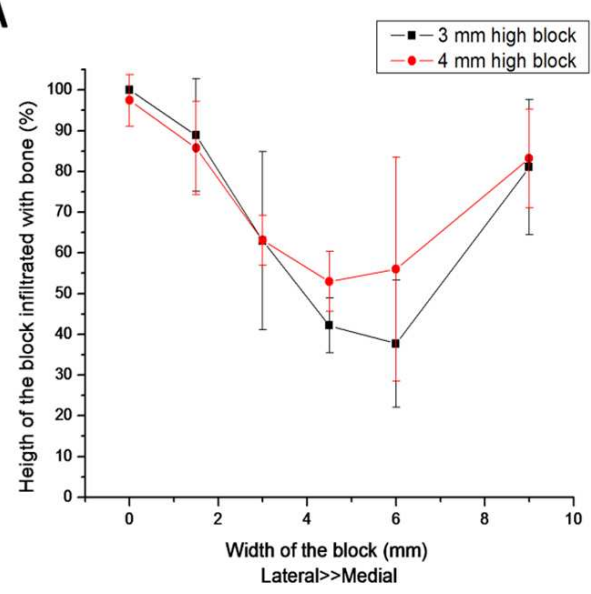

B

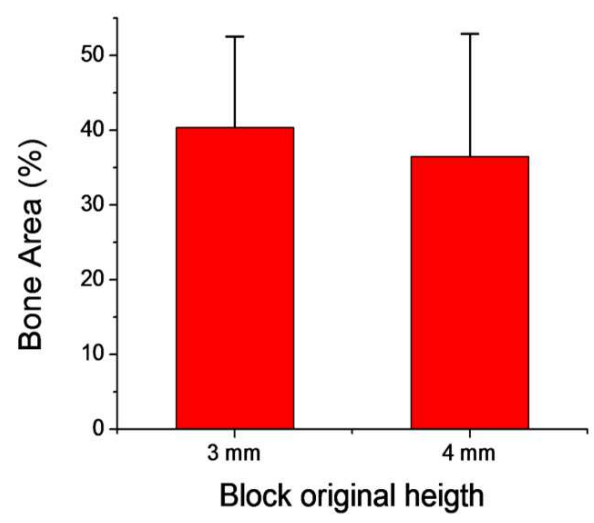

Figure 5. A: Relative bone height gained along the mediolateral axis of the blocks. The measurements represent the percentage of bone height gained between the original calvarial surface and the superior surface of the monetite blocks. The lateral end of the blocks achieved the maximum percentage of bone height augmentation in both blocks. The central part shows approximately $50 \%$ of bone height augmentation and medial side reached between $70-80 \%$ of bone height formation. B: the percentage of bone tissue measured within the blocks' augmented area. $265 \times 117 \mathrm{~mm}(137 \times 150 \mathrm{DPI})$ 